https://helda.helsinki.fi

\title{
Death in Sauna Associated With a Transdermal Fentanyl Patch
}

\section{Kriikku, Pirkko}

2020-12

Kriikku , P , Ojanpera , I \& Lunetta , P 2020 , ' Death in Sauna Associated With a

Transdermal Fentanyl Patch ' , The American Journal of Forensic Medicine and Pathology , vol. 41 , no. 4 , pp. 313-314 . https://doi.org/10.1097/PAF.0000000000000565

http://hdl.handle.net/10138/336956

https://doi.org/10.1097/PAF.0000000000000565

cc_by_nc

acceptedVersion

Downloaded from Helda, University of Helsinki institutional repository.

This is an electronic reprint of the original article.

This reprint may differ from the original in pagination and typographic detail.

Please cite the original version. 


\section{Death in sauna associated with a transdermal fentanyl patch}

Pirkko Kriikku, PhD

- Finnish Institute for Health and Welfare, Forensic toxicology unit, Helsinki, Finland

- Department of Forensic Medicine, University of Helsinki, Finland

Ilkka Ojanperä, PhD, Professor

- Department of Forensic Medicine, University of Helsinki, Finland

- Finnish Institute for Health and Welfare, Forensic toxicology unit, Helsinki, Finland

Philippe Lunetta' MD, Professor

- Department of Biomedicine, Forensic Medicine, University of Turku, Finland

- Department of Forensic Medicine, Research Unit of Internal Medicine, University of Oulu

Corresponding author:

Pirkko Kriikku

Finnish Institute for Health and Welfare

Forensic toxicology unit

P.O.Box 30

00271 Helsinki, Finland

Tel. +358295248054

Email: pirkko.kriikku@thl.fi

No external support or funding was received for this project 


\begin{abstract}
We present a case of an accidental fatal fentanyl overdose caused by increased uptake of the drug from a transdermal patch while experiencing the heat of a sauna.

The transdermal patch administers fentanyl at a relatively constant rate through the skin. However, in the subcutaneous tissue blood circulation greatly influences the rate of this drug's systemic intake. In the present case, an elderly woman with multiple health conditions was prescribed fentanyl patches but was unaware of the risks associated with external heat sources when one wears the patch. She was found dead in the sauna with a post-mortem femoral blood concentration of fentanyl that was elevated $(15 \mu \mathrm{g} / \mathrm{L})$. The cause of death was determined to be fatal poisoning by fentanyl with the contributing factor of external heat from the sauna.

Risks associated with transdermal administration of a potent opioid like fentanyl are widely described in the scientific literature and described in the manufacturer's summary of product characteristics. Physicians and pharmacists should take particular care to ensure that patients understand these risks.
\end{abstract}

Keywords:

Fentanyl, transdermal patch, opioid intoxication, sauna

\title{
Highlights
}

- Heat may increase the intake of transdermally administered fentanyl

- Patients using fentanyl patches may be unaware of the risks

- A sauna is one of the heat sources to avoid when using fentanyl patches 


\section{Introduction}

Fentanyl is a potent synthetic opioid analgesic to treat severe chronic pain and cancer patients' breakthrough pain. Fentanyl administration can be by injection, transdermal patch, tablet, rectal preparation, buccal film, or nasal spray, with an increasing preference for the transdermal formulation.

After patch application, fentanyl is absorbed into the subcutaneous tissue slowly, at a relatively constant rate, for up to 72 hours. From the tissue, fentanyl is then released into the systemic blood circulation by diffusion. Because absorption of fentanyl from a transdermal patch is highly dependent on rate of cutaneous blood flow, changes in temperature affecting flow will exert a major effect.

The manufacturer of Duragesic $®$ patches warns that fentanyl blood concentration may increase considerably (such as by 61\%) after administration of moderate heat close to the patch area. ${ }^{1}$ One study involved moderate heat application to accelerate onset of the sedative effects; peak plasma fentanyl concentration and the area under the curve (AUC) were fourfold that of the control group without heat application. ${ }^{2}$

In other reports on heat-induced intoxication and other adverse effects of fentanyl after transdermal administration, ${ }^{3}$ effects were severe but non-fatal and occurred after using a heating pad ${ }^{4}$ or blanket, ${ }^{5}$ falling asleep in the sun, ${ }^{6}$ or engaging in outdoor activities in a sunny environment. ${ }^{7}$ A recent report from another sauna country, Sweden, described a patient receiving transdermal fentanyl treatment who, after a sauna, suffered a non-fatal intoxication. ${ }^{8}$ To our knowledge, our report is, however, the first of a fatal outcome resulting from a sauna causing an overdose of fentanyl.

\section{Case report}

\section{Case history}

On October 17th at 11.00 a.m. a Caucasian female in her eighties was found dead, naked and lying supine, partially on her right side, on the top bench of an electrically heated sauna in the care home where she lived. The victim's personal walking frame was inside the sauna, near the benches. No resuscitation attempts were performed because secondary signs of death were evident. A police investigation revealed no suicide note nor findings suggesting foul play.

\section{Medical history}

The victim's medical history included scoliosis, intervertebral disc degeneration, generalised arthritis, osteoporosis, and IgG monoclonal gammopathy. Her MMSE (Mini-Mental State Examination) score was 26/30. For back pain, the victim's prescription of tramadol was initially replaced by oxycodone and then by a fentanyl patch (Durogesic ${ }^{\circledR}, 50 \mu \mathrm{g} / \mathrm{h}$ ) that a nurse changed every three days. Approximately a week before death, a second fentanyl patch (Durogesic $®, 12 \mu \mathrm{g} / \mathrm{h}$ ) was added. In addition, the victim was prescribed duloxetine 
(Cymbalta $₫ 30 \mathrm{mg}, 60 \mathrm{mg}$ ), thyroxine (Thyroxin $₫ 25 \mu \mathrm{g}$ ), glucosamine sulphate (Artryl $\AA 750$ $\mathrm{mg}$ ), and -if necessary-acetaminophen (Panadol forte $\AA 1 \mathrm{~g}$ ) and alprazolam (Xanor $₫ 0.25$ $\mathrm{mg}$ ). According to information available at the autopsy, the victim received no advice as to any need to avoid exposure to heat such as from a sauna while wearing fentanyl patches. One of the victim's next of kin reported that during a recent sauna, she had experienced some visual hallucinations.

\section{Autopsy findings}

The medico-legal autopsy was performed seven days post-mortem. At external examination, the victim's body showed some mild burn-like skin lesion caused by exposure to heat in the sauna, and a few scattered bruises on the upper arms and left inner arm, but no other sign of mechanical trauma. The right scapular region disclosed two fentanyl patches (Durogesic ${ }^{\circledR} 12$ $\mu \mathrm{g} / \mathrm{h}$, Durogesic $\AA^{2} 50 \mu \mathrm{g} / \mathrm{h}$ ). Internal macroscopic and microscopic examination disclosed in addition to generalised atherosclerosis, mild coronary artery disease, mild lung fibrosis, and mild nephrosclerosis. The brain and lungs were congested, and the lungs showed signs of oedema.

\section{Toxicological analysis}

Post-mortem blood from the femoral vein was positive by liquid chromatography-tandem mass spectrometry for fentanyl $(15 \mu \mathrm{g} / \mathrm{L})$, as well as for duloxetine $(0.19 \mathrm{mg} / \mathrm{L})$ and paracetamol (22 $\mathrm{mg} / \mathrm{L}$ ), detected by ultra-high-performance liquid chromatography with a photodiode array and charged aerosol detection. Fentanyl was also detected in the vitreous humour by liquid chromatography with time-of-flight mass spectrometry. The blood and vitreous humour tested negative for alcohol. In addition, traces of caffeine $(6.5 \mathrm{mg} / \mathrm{L})$ were in the blood, but no other relevant findings were detectable.

The cause of death was certified as "fatal poisoning by fentanyl" and the manner of death "unintentional". "The effects of elevated temperature (hot air, sauna)" were deemed a contributing cause of death.

\section{Discussion}

We report a case of the fatal fentanyl poisoning of an elderly woman with multiple severe health conditions. The mild atherosclerotic changes in the coronaries and mild lung fibrosis have likely played no significant role in the events leading to death. The heat of a sauna caused elevated systemic intake of fentanyl from two transdermal patches, leading to a high blood concentration and eventually to her death.

The effects of heat on delivery of fentanyl from transdermal patches are widely described, both in the scientific literature and in the summary of product characteristics (SPC) accompanying the products. Because fentanyl can cause respiratory depression and fatal poisoning, even in relatively low concentrations, advice for both user and the prescribing physician is rather lengthy. In addition to what needs to be taken into consideration when prescribing fentanyl patches to patients with different medical conditions, the SPC also 
advises that the patient should avoid external sources of heat while having the patch attached to their skin since high temperatures can increase the speed that fentanyl is delivered from the patch. Fever can also elevate concentrations above those administered requiring monitoring and possible dosage change. In the case reported here, such vital information regarding fentanyl influenced neither this patient's behaviour nor that of her caregivers.

A fentanyl concentration measured post-mortem is not alone sufficient to suggest a fatal fentanyl poisoning case. Therapeutic plasma concentrations of fentanyl in living subjects after transdermal application are generally below $2.5 \mu \mathrm{g} / \mathrm{L}^{9}$ but there is high inter-individual variability, and plasma steady-state concentrations of up to $8.3 \mu \mathrm{g} / \mathrm{l}$ have been reported. ${ }^{10}$ Fentanyl plasma or blood concentrations do not correlate well with transdermal fentanyl doses, and furthermore, post-mortem fentanyl concentrations can be considerably higher than the plasma concentrations of living subjects wearing fentanyl patches due to postmortem redistribution. ${ }^{11}$ Reiter et al $^{12}$ studied the post-mortem increase of fentanyl blood concentrations in ten palliative care patients that died following treatment with fentanyl patches with delivery rates of $12-150 \mu \mathrm{g} / \mathrm{h}$. The post-mortem blood fentanyl concentration was above $10 \mu \mathrm{g} / \mathrm{l}$ in two out of 25 measurements from five subjects having patches of 50-75 $\mu \mathrm{g} / \mathrm{h}$.

In our case, the femoral blood fentanyl concentration $(15 \mu \mathrm{g} / \mathrm{L})$ was high considering the dose of $50 \mu \mathrm{g} / \mathrm{h}+12 \mu \mathrm{g} / \mathrm{h}$. The concentration was above the post-mortem median fentanyl concentration from all causes of death reported in a recent compilation $(4.2 \mu \mathrm{g} / \mathrm{L}, \mathrm{N}=1074) .{ }^{13}$ However, the possibility that the result was affected by post-mortem redistribution cannot be excluded. On non-fatal heat-associated intoxication cases reported in the literature ${ }^{4-8}$ we have no blood concentrations available for comparison. However, Baselt ${ }^{14}$ has referred to a case of a 32-year-old man wearing a $100 \mu \mathrm{g} / \mathrm{h}$ transdermal patch dying following physical exertion on a very hot day and showing a femoral-blood fentanyl concentration of $20 \mu \mathrm{g} / \mathrm{L}$.

In Finland and in some other cool climate countries, many residents take a sauna at least once a week so they require special attention as to the dangers associated with transdermal fentanyl preparations in a hot environment. Elevated drug concentrations can lead to intoxication, respiratory depression, and death. Since delivery of fentanyl from a subcutaneous drug reservoir does not cease immediately upon removal of a patch, before entering a sauna or being exposed to any other situation that increase blood circulation in the subcutaneous tissue, warnings are vital.

\section{References}

1. Durogesic®. (2019). Summary of product characteristics (SPC), Janssen-Cilag, 4 Sept 2019. Available at: http://spc.fimea.fi/indox/nam/html/nam/humspc/6/867876.pdf (in Finnish). Accessed 24 October, 2019. 
2. Shomaker TS, Zhang J, Ashburn MA. Assessing the impact of heat on the systemic delivery of fentanyl through the transdermal fentanyl delivery system. Pain Med. 2000;1:225-230.

3. Carter KA. Heat-associated increase in transdermal fentanyl absorption. Am. J. Health Syst. Pharm. 2003;60:191-192.

4. Rose PG, Macfee MS, Boswell MV. Fentanyl transdermal system overdose secondary to cutaneous hyperthermia. Anesth. Analg. 1993;77:390-391.

5. Frölich M, Giannotti A, Modell JH. Opioid overdose in a patient using a fentanyl patch during treatment with a warming blanket. Anesth. Analg. 2001;93:647-648.

6. Sindali K, Sherry K, Sen S, et.al. Life-threatening coma and full-thickness sunburn in a patient treated with transdermal fentanyl patches: a case report. J. Med. Case Rep. 2012;6:220.

7. Newshan G. Heat-related toxicity with the fentanyl transdermal patch. J. Pain Symptom Manag. 1998;16:277.

8. Hessulf F. Can't take the heat: sauna and fentanyl patch intoxication. Clin. Toxicol. $2019 ; 57: 219$.

9. Muijsers RB, Wagstaff AJ. Transdermal fentanyl: an updated review of its pharmacological properties and therapeutic efficacy in chronic cancer pain control. Drugs. 2001;61:2289307.

10. Solassol I, Bressolle F, Caumette L, Garcia F, Poujol S, Culine S, Pinguet F. Inter- and intraindividual variabilities in pharmacokinetics of fentanyl after repeated 72-hour transdermal applications in cancer pain patients. Ther. Drug Monit. 2005;27:491-8. 
11. Andresen H, Gullans A, Veselinovic M, Anders S, Schmoldt A, Iwersen-Bergmann S, Mueller A. Fentanyl: toxic or therapeutic? Postmortem and antemortem blood concentrations after transdermal fentanyl application. J. Anal. Toxicol. 2012;36:182-94.

12. Reiter A, Mueller A, Otto B, Anders S, Falckenberg M, Iwersen-Bergmann S, AndresenStreichert H. Fast increase of postmortem fentanyl blood concentrations after transdermal application: A call to careful interpretation. Forensic Sci. Int. 2019;302:109896.

13. Ketola RA, Ojanperä A. Summary statistics for drug concentrations in post-mortem femoral blood representing all causes of death. Drug Test. Anal. 2019;11:1326-1337.

14. Baselt RC. Disposition of Toxic Drugs and Chemicals in Man, 11th ed., Seal Beach, CA: Biomedical Publications; 2000:884. 